\title{
Comercio y cultura: Imanes de sueños sociales
}
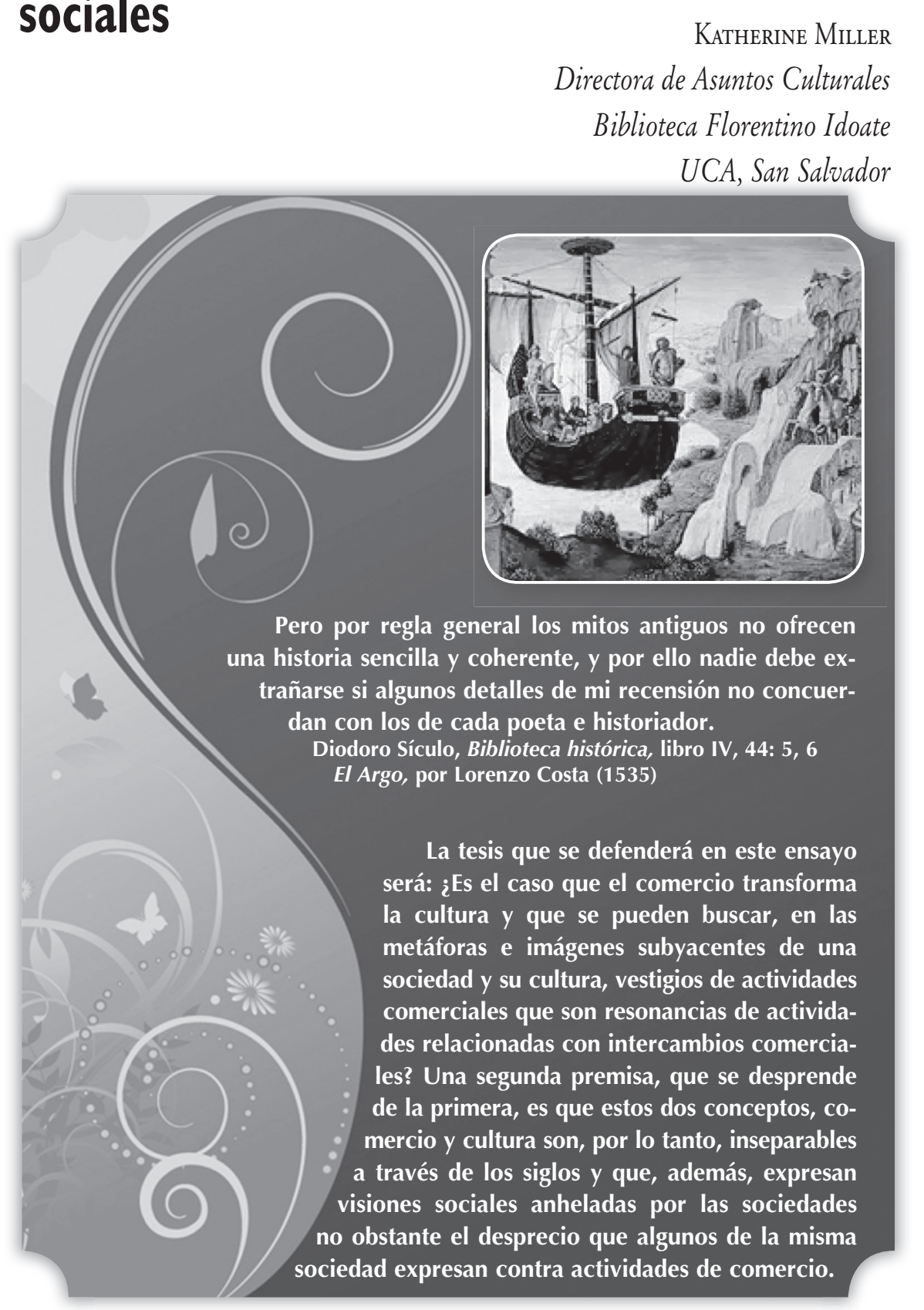
Es nuestra intención presentar un año de estudio sobre la relación entre estos dos fenómenos - comercio y cultura- comenzando con los griegos antiguos y continuando hasta la fragmentación del Imperio Romano y la Antigüedad Tardía, pasando por la relación del comercio con el teatro y drama en Europa Occidental durante la Modernidad Temprana, y terminando con un examen de la relación de actividades de comercio y cómo éstas le dieron forma a la novela victoriana en el desarrollo del imperio de agua azul de Gran Bretaña.

Por ahora, nos limitamos al primer segmento del curso, que lleva por título "El comercio y la cultura", y comenzaremos con la Antigüedad en la cuenca del Mediterráneo.

Siguiendo las líneas de investigación indicados por Diodoro Sículo en sus comentarios de su Bibliotheca Histórica (citados arriba), este historiador griego del primer siglo que vivía en la actual Sicilia, en la Magna Grecia, afirma que la metamorfosis de los mitos en historia o poesía no es sencilla ni coherente. La esencia de la transformación que se detectan en las líneas que conectan artefactos y actividades, es que sufren cambios en que están transformados en artefactos culturales como poemas y drama que, por ser artefactos culturales son, necesariamente, separados de la realidad cotidiana: digamos, de la realidad nacional. En este sentido la literatura es, a veces, una expresión de sueños sociales, o de las visiones del futuro. Es una manera de visualizar e internalizar lo que nos sobreviene y no se detiene.

Este es el caso de las posibilidades de una vida marítima en un pequeño país en la costa del Océano Pacífico. En otros tiempos y otros espacios geográficos, los mitos marítimos energizantes para un pueblo han expresado una separación entre las actividades del comercio y sus expresiones culturales. El comercio es transformado en la cultura $y$ la cultura es transformada en una expresión de las actividades del comercio, en este caso, para empezar, en el comercio marítimo internacional en la vida de un pueblo.

No hay duda que el intercambio comercial -el comercio marítimo internacional- siempre trae cambios. Lo que es nuevo, sin embargo-aunque es, en realidad, antiguo-usualmente trae resistencia a cambios, especialmente cuando los cambios son tan grandes como los que se nos avecina con la activación de los puertos en la costa pacífica de América Central. Inevitablemente, se construirán carreteras y canales secos, se integrarán aduanas y aeropuertos, además de todas las nuevas concepciones en el desarrollo de ciudades portuarias. Todo ello representa una reasignación de espacios culturales en una sociedad. 
Puede que estos puertos traigan, también, cambios en los mitos nacionales en que comenzarán a aparecer visiones, talvez, de una república marítima como plataforma de integración regional fomentada por actores internacionales.

Pero, a la misma vez, ¿es el caso que nos asusta la apertura a otras culturas y costumbres que el comercio marítimo internacional nos traería, inevitablemente? El Salvador no ha tenido contacto amplio - aislado, así como está en la costa Pacífica - con las culturas de la Unión Europea, la India, China continental, Indonesia y otros países que inevitablemente Ilegarían a las puertas en un afán comercial y, por lo tanto, penetran las esferas culturales del país.

¿Es el caso que estamos concentrados en las pretensiones sociales y nostalgia de grandeza de un pasado agrícola hasta el punto de un solipsismo cultural? ¿Estaremos, desde esta óptica, parecidos a los elegantes sureños de los Estados Unidos de América antes de la Guerra Civil, aferrados a su cultura nacional en los tiempos del cultivo de añil, algodón y café pero defendiendo la esclavitud?

¿O es que se puede sentir miedo a cargar con el olor que viene con el trabajo en las muelles? Es posible que se anhela siempre un pasado dorado de la cultura de los antepasados en que el folclor rural tiene ascendencia y se resiste y se cierre a lo que es nuevo: es decir, otras culturas que vienen con el comercio marítimo. Por cierto, seguramente veremos nuevos sueños y nuevas pesadillas, esquemas que no encajen con la realidad nacional y el status quo cultural. Todavía. Hay un desfase entre la realidad que viene encima y su manifestación cultural.

Siempre ha habido una falta de resonancia - por no decir tensiónentre los que se dedicaban al comercio, sea industrial o marítimo, y los que se dedicaban a la fabricación de una cultura nostálgica. Pero la modernidad huele a cambios continuos en el modo de vivir, especialmente a causa de la intromisión de otras culturas en la cultura nostálgica. Por los objetivos de este argumento, no se está hablando de avances tecnológicas, si no de la esfera del impacto de lo que es ajeno y extranjero que trae el comercio a una cultura.

Sumergidos en esta red tejida de sueños, folklore, restricciones, privilegios, prácticas y celebraciones que nos vinculan a la naturaleza de un pasado compuesto de una neblina luminosa de los ancestros se puede rechazar la conflación de otras modalidades culturales que provienen de los cambios profundos en las prácticas comerciales internacionales.

Puede que haya resonancias con las prácticas sociales de los británicos de la época de la reina 
Victoria, quienes, durante el siglo XIX — cuando Karl Marx estaba escribiendo Das Kapital en el Museo Británico- sentían horror y angustia ante la posibilidad - $\mathrm{O}$ necesidad- de caer en la categoría social "of being in trade" — trabajando en el comercio, siendo mercader o comerciante y no practicante puro de la política y el arte del estado.

Los "Manchester Men" del norte de Inglaterra, con sus fábricas textileras quedaron muy lejos de obtener ni siquiera una mención en una conversación cortés de una cena familiar o social durante el auge de la Revolución Industrial. Con eso, se puede presentar la aseveración de que este fenómeno de rechazo y desprecio a actividades comerciales e industriales es transformado culturalmente a otras formas. (Por medio de ilustración, podría ser lo que hizo el eminente novelista victoriano, Bram Stoker, quien, durante el mismo período de industrialización, transformó en novela los miedos primordiales de los buenos ingleses contra la inmigración de personas que buscaban trabajo en las fábricas provenientes desde Europa Central a Inglaterra. Los miedos los transformó en pesadillas de vampiros que chupaban la sangre de la sociedad victoriana [véase Dracula (1897)].

Pero las raíces del repudio y del desprecio de las actividades comerciales en sus formas mas antiguas están representadas en sombras en los escritos de Platón en sus prejuicios contra los artes mercantilistas, rechazaba —especialmente- el comercio al por menor.

Además, la práctica de la política, del arte del estado, se ha alejado la clase política de los estamentos de los que practican los artes comerciales. Hay una brecha, una ruptura profunda que se percibe entre la televisión y en los periódicos, entre los empresarios y el gobierno. Platón puede ser el culpable original de este desprecio de comercio y actividades comerciales en el imaginario social de Europa importado por estos lados.

Veamos primero a Platón, el filósofo político de los políticos que desprecian a los empresarios y animan a un complejo de superioridad hacia los que se dedican al arte del estado. Estas actitudes se han filtrado en líneas de continuidad desde Platón y podemos examinarlos explícitamente en su último libro, Las leyes.

Si bien es cierto, como alega algún pensador prestigioso, que la civilización occidental es solamente una nota al pie del pensamiento de Platón, este griego eminente, podemos ver en sus obras que más que cualquier otro arte adquisitivo, el comercio al por menor es una tentación al ciudadano de bajarse moralmente a un comercialismo degradante, estimulando su ansia para ganancias. 
En su última obra, Las leyes, Platón declara que cualquier ciudadano terrateniente, de las clases altas, quien se dedica al comercio al minoreo, deberá ser castigado con encarcelamiento, porque solamente extranjeros residentes están permitidos a este arte de intercambio comercial al minoreo. [The Laws, traducido por Benjamin Jowett, XI, $920^{\mathrm{a}}$.

$Y$ es posible que las invocaciones y execraciones de hoy contra el consumismo provienen de la proclamación de Platón que se debe ejercer control moral contra los deseos adquisitivos y así resolver la decadencia de la polis. (Se dice, públicamente hoy, hasta en las publicaciones de una universidad reconocida, que participar en la cultura requiere el rechazo del consumismo comercial).

En La República de Platón, Glaucón se enfrenta contra el autor —su hermano estricto y ascético-, y contra un estado igualmente ascético y pide comodidad, más y mejores bienes y servicios especializados como música, artes, etc. Pero, responde su hermano estricto: esto que pides requiere mas producción y comercio y mercados que se desarrollan con vendedores ambulantes y tiendas, mercaderes de larga distancia e intercambios marítimos comerciales. Eso, dice el hermano de Glaucón, produce un estado lujurioso con una actividad febril, en que los deseos adquisiti- vos causan cupiditas y usura que se encuentran atrás de cada esquina y debajo de las camas. La comodidad y la opulencia rompen con la armonía social de un estado ascético y virtuoso. (¡Que viva la pobreza!) Termina su respuesta a Glaucón al declarar que donde el espíritu empresarial, estimulado por deseos insaciables, asume el control de la sociedad y donde el pueblo junto a los mercaderes agarra la palanca de acumulación, la virtud cívica escapa de los patrones y los moldes tradicionales y desemboca en la ruptura de la cohesión social lo cual resulta en una guerra entre los ricos y pobres (Republica, VIII, $551 \mathrm{~d}$ de la traducción de Benjamin Jowett).

Estos son las categorías de un imaginario social que pasan por ser las únicas "culturas" imaginables fomentado por un costumbrismo de corte férreo en la educación nacional. Estas categorías coexisten paralelas a la realidad nacional y al trabajo diario y arduo en las fábricas, en las calles, en los campos y en las casas. Se escuchan los ecos de esta construcción mental y cultural en el comentario reciente, y muy ilustrativo, de un joven que trabaja en una fábrica. Hablando de EI Salvador, dijo: "Mi país es un país muy folclórico." El pasado dorado permanece simultáneamente entre las prensas cortadoras y máquinas a coser.

El comercio marítimo internacional traerá consigo todo lo 
que trajo a Odiseo, "saqueador de ciudades" (léase, pirata o mercader marítimo). En la nueva y definitiva traducción al inglés de la Odisea por Robert Fagles, escuchamos a Odiseo declarando que "I have plundered the city of Troy" [He saqueado la ciudad de Troya]. Y cuando Odiseo quiso hablar con el profeta Tiresias y con su madre para reafirmar quién era y ver su futuro, viajó al bajo mundo e hizo sacrificios de la sangre de ovejas para que la sombra de Tiresias pudo beber de la sangre (acto necesario para las sombras y espíritus de los muertos griegos que desean hablar con los mortales en vida) y cobrar vida para conversar con Odiseo y predecir, en forma humana, el futuro, asumiendo una forma en que Odiseo pudo entenderlo.

Para explorar el imaginario social de futuras culturas que nos viene encima con la imposición de la realidad de la expansión portuaria y la apertura del país a nuevos mundos, talvez las sombras del presente pueden beber la sangre del pasado, metafóricamente, para conversar con nosotros - como Tiresias conversó con Odiseo- - y así poder vislumbrar el futuro, nublado y con formas todavía imperceptibles. Hasta puede ser posible hundir las diferencias ideológicas del presente en los imperativos del futuro. El pasado puede ser un espejo para el futuro. Y los pensadores hoy pueden beber la sangre de los escritores del pasado porque hay una línea de continuidad entre este entonces y la historia del presente en las obras literarias -y en la sociedad mediática del diario sabiduría proyectado a la ciudadanía. Todo eso se ve cargado con temas subyacentes de la posible riqueza del comercio marítimo.

Para acercarnos a este tema, en este ensayo, no se va a adherirse a ningún lado ideológico de las riendas políticas actuales. Pero siendo conciente de las navajas que brillan y destellan en la periferia, se va a partir de una provincia, del terreno de una zona de seguridad que no está en disputa: el desarrollo histórico de la cultura intercalado con las

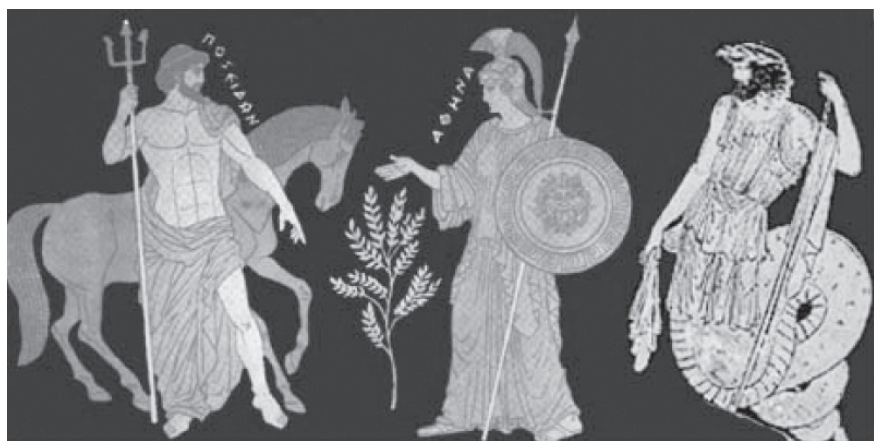

Poseidón ofrece el caballo y Palas Atenea, el olivo, a la ciudad de Atenas 
rutas marítimas como pasaje para la interrelación entre el comercio y el estado. Digamos, para comenzar, entre Agamenón y Aquiles y aquella ciudad enormemente rica por su comercio con el oriente: la ciudad ubicada en el traspaso entre el Mar Egeo y el Mar Negro, en la esquina del Bósforo: Troya, centro de una serie de rutas comerciales, marítimas y terrestres, Troya en la Costa Pacífica del Cono del Sur.

Para evitar la osificación intelectual y literaria que es la característica de la mayoría de las consideraciones del poema de Homero, comenzamos con una definición de apoyo para el acercamiento que propongo. El análisis de la cultura en conjunto con el desarrollo del comercio es que las causas últimas de la lucha entre los dos fenómenos se pueden encontrar en el conflicto de corrientes de pensamiento conceptos- que presentan perspectivas solamente en su propio tiempo.

La Grecia antigua es una península rocosa con un suelo poco productivo: hay un friso o cenefa de la antigua Grecia que presenta a Poseidón regalando el caballo a los griegos que deseaban formar una ciudad; mientras que Palas Atena, la diosa que los romanos Ilamaron Minerva, regala a los griegos el olivo y el cultivo del mismo. Así, la ciudad se llamaba Athenaeae (la ciudad de Atenea) de los regalos de los dioses, el caballo y el olivo. Este último era considerado más necesario, por ser alimento. Los granos básicos para la alimentación de la población y su sobrevivencia fueron importados al Peloponeso desde Egipto, que tenía un suelo fuertemente fértil. Lo que nos lleva de vuelta al comercio marítimo internacional.

También Ilegaron desde Egipto a Atenas no solamente granos básicos como el trigo a Atenas, sino también joyas, cerámicas y aceites aromáticos hechos de las flores para bañarse los pueblos y para encubrir los olores apestosos de los altares donde sacrificaron los animales. La cultura griega requería de perfumes y aceites fragantes de Egipto. La cultura refleja - es- el comercio.

Hay un escritor griego que nos permite apreciar los productos del comercio marítimo internacional del siglo V A. de C. Es el dramaturgo Hermippus, quien recita, en un fragmento de una de sus comedias, The Basket-bearers (cargadores de cestas), lista de las riquezas alimenticias que llegan a Grecia provenientes de la Cuenca Oriental del Mediterráneo.

Hermippus era un dramaturgo de la Antigua Comedia Griega, de la generación antes de Aristófanes (s. V, a. de C.) y aquí celebra el comercio e intercambio cultural del Mediterráneo: 
Ahora, cuéntame, Musas, moradoras de Olimpia, cuáles bienes trajo Dionisio para los pueblos en su barco negro, desde cuando él comerciaba sobre el mar oscuro como el vino. Desde Cirene, tajos de sílfide y cueros de bueyes, desde el Helesponto, caballas y cada clase de pescado salado, desde Tesalia, harina fina y costillas de res. Y de Sitalces la picazón para los espartanos. Desde Perdiccas, barcos llenas de mentiras. Y los siracusanos nos abastecen con cerdos y queso; Y los de Córcira - ruégole a Poseidón que destruya sus barcos, porque tienen entusiasmo por ambos lados. Desde Egipto, velas alzadas y libros. $Y$ desde Siria, más allá, (incienso franquincense). Y la isla fina de Creta provee ciprés para los dioses. Y Libia, marfil abundante para vender; Rodas [envía] uvas y pasas e higos dulces como sueños. Además, desde Euboea, peras y manzanas. Esclavos desde Frigia y desde Arcadia, mercenarios. Pagasae provee esclavos y marcas para esclavos Paflagonia envía los bellotas de Zeus y almendras luminosas. Sirven para ornamentar los banquetes. Fenicia, además, [envía] frutas de las palmeras y harina fina de trigo. Cartago [envía] alfombras y almohadas de muchos colores.

[Hermippus, apud Athenaeus, I.27e. Citado en Kassel, R. y C. Austin. Poeta Comici Graci I. Comoedia Dorica Mimi Phlyaces. (Berlín, 2001)(Traducción propia).

Pero los ojos de los griegos, aventureros-piratas-comerciantesguerreros-mercenarios, se habían vuelto hacia el oriente y hacia sus alimentos y otras riquezas. Primero, los que más tarde fueron Ilamados griegos, capturan a Knossos de Minoa, y después, el comercio de los hititas en la Isla de Ciprés, seguido por las rutas marítimas comerciales en el Levante, entonces Mileto en el Asia Menor (Turquía). Estos eran los micenos, aqueos y argivos de los que nos cuenta Homero y a los que los romanos denominaron "griegos". Desarrollaron rutas marítimas, construyeron barcos, comenzaron asentamientos humanos y comer- ciales en Asia y en el Levante. Hay documentación de obligaciones de tratados entre Ilión (léase, Troya) y los hititas de Asia Menor, donde queda Troya. La interrelación entre comercio y cultura sigue en línea directa desde este entonces.

Jenofonte nos cuenta que la riqueza de Atenas y su puerta en el Pireo se basaba en el comercio marítimo (On Revenues, literalmente, Del fisco,. 4331-355 a. de C.) Exportó pescado salado, frutas cítricas y plata de las minas en Anfípolis donde Tucídides y su familia eran dueños de las minas. 
Llegando al siglo $\mathrm{V}$ a. de $\mathrm{C}$., Atenas era una ciudad rica y poderosa, hasta el punto que Esparta temía el poder de Atenas y su Liga de Delos, como cuenta Tucídides. Egipto exportó el trigo que Atenas necesitaba para alimentarse y así los griegos de Atenas ayudaban a los egipcios levantar una insurrección contra los persas (los habitantes del actual Irán), quienes ocuparon el país. Las guerras tenían como objetivo el control de estas rutas marítimas y sus ciudades portuarias, enormemente importantes, no solamente para los lujos, sino también para la alimentación y la sobrevivencia.

En la hora en que se produce la Iliada (ca. S. VIII a. de C.), la ciudad de Troya, en la actual Turquía, recibió en calidad de intercambios comerciales toda la riqueza de Asia Central y Oriente. Era un centro comercial, la cruzada de rutas marítimas y terrestres. Los hambrientos guerreros-cum-piratas de Micena montaron una expedición para conquistar la ciudad. Helena posiblemente existía, pero si existía como mujer histórica raptada por Paris en un viaje diplomático a Micena en que representaba a los troyanos ante los micenos. Helena siempre ha representado la más bellas riquezas de oro, seda y alimentos disponibles en Troya.

Ahora, la cultura antropológica y literaria, mítica, que rodea la expedición de Menelao para conquistar "lo que era de él", es de enormes dimensiones. Los esfuerzos para cumplir con este propósito se ven en la unificación de las tribus de la península del Peloponeso. En la Iliada Homero celebra dichos esfuerzos en el catálogo de barcos, el sacrificio de su hija Ifigeneia para levantar los vientos para la flota, en las luchas sectarias entre los tribus, ejemplificados en el enfrentamiento de Menalao de Micena contra Aquiles y sus mirmidones por el botín de una mujer raptada. El poema celebra con violencia y furia la unificación de tribus griegas y revela los pleitos sectarios y tribales para montar la flota que tomaría control de la riqueza del comercio necesario para la sobrevivencia y alimentación de los griegos del Peloponeso, saqueándolo las ciudades de Asia. Y el poeta envuelve estas actividades esencialmente comerciales en un disfraz metafórico que es una celebración de la fuerza y violencia que requería el comercio marítimo internacional.

Piratas, aventureros, saqueadores de ciudades, los griegos estaban ansiosos para la riqueza del comercio para el bienestar material de sus pueblos. Es por eso que la expedición marítima de los griegos del Peloponeso conquistó otros griegos más ricos en Anatolia. Al fin de tanto, Príamo y Menelao, ambos, hablan dialectos del griego que son mutuamente comprensibles en las conversaciones y negociaciones que el poema presenta. 


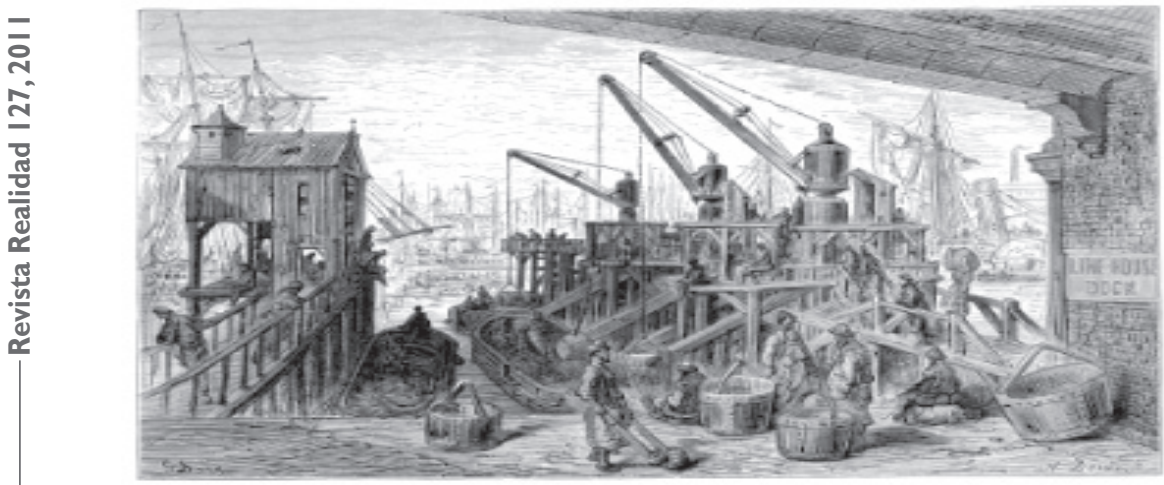

Grúas antiguas en una puerta mediterránea

Obviamente esta no es la única interpretación. Pero es una interpretación subyacente, aunque la elegancia literaria también se presta a muchas interpretaciones multifacéticas y simultáneas. El poema celebra un acto de comercio-cum-saqueocum-piratería. ¿Cómo se distingue entre el comercio y la piratería ante la ausencia de leyes marítimas y la arbitrariedad ante la ausencia de tratados de libre comercio? El punto es que en la llíada, el comercio inspira la cultura y la cultura literaria - y oral, por supuesto- se apodera del comercio como uno de sus temas principales. ¿Dónde está el poeta del comercio marítimo de la costa Pacífica actual?

Ahora, en la Odisea, escuchamos a Odiseo cuando, al llegar a Ítaca, miente ágilmente a Palas Atenea (que está disfrazada). Odiseo le asegura a esta última que él es un mercader de Creta. Lo importante de este episodio es que revela que en esta sociedad antigua no solamente había mercaderes, sino que el hecho de ser mercader pasaba por una profesión bien definida, aparentemente respetable, dado que el gran guerrero-marinero-saqueador de ciudades, Odiseo, desea hacerse pasar por un mercader en trabajos de comercio marítimo en una isla tan importante como Creta. No es tan sorprendente, pues, que Odiseo, "saqueador de ciudades", se llame mercader ante la diosa.

Llegando al siglo III a. de C., el viaje para capturar el vellocino de oro, emblema sobresaliente de riqueza y su producción que puede ser raptado, captura la imaginación del poeta egipcio, Apolonio de Rodas, poeta y bibliotecario de la gran Biblioteca de Alejandría. La búsqueda de riquezas puede interpretarse en la obra La argonáutica en el sentido de que todos los héroes del mundo griego, Orfeo, Polifemo, los hijos de Poseidón y muchos más, son los marineros griegos que cruzan el Mar Negro para apoderarse del oro. ¿Una forma de intercambio comercial, piratería? 
Jasón tiene que hacer varios gestos heroicos y también rapta a Medea junto con el vellocino de oro (léase la riqueza de la Cólquide en las orillas del Mar Negro y de Asia Central -la actual Georgia, en las vecindades de Rusia-) y llevarlo a Corinto en Grecia. El vellocino representa la riqueza que Jasón lleva a la ciudad de comercio y mercaderes par excelence, Corinto. Ésta era una de las ciudades portuarias más importantes, tan suntuosa y sibarítica que San Pablo, siglos después, alude a esta ciudad como el colmo de comportamiento lascivo (y en eso, sigue a Platón, que tanto tuvo que ver en la influencia sobre la teología de los cristianos). Corinto era central en el comercio de Grecia en la Megáride (istmo que se encuentra en medio de la península del Peloponeso). Y eso es donde Jasón regresa con el vellocino de oro - y con Medea a Corinto.

Apolonio escribe el fantasioso viaje de Jasón hasta el final de la tierra $-\mathrm{O}$, por lo menos, hasta el otro lado del Mar Negro- hasta llegar a la ciudad de la Cólquide donde el oro era abundante. Los pueblos de la Cólquide buscaban el oro de los riachuelos por medio de un procedimiento en que se sumerge un vellocino de oveja en la corriente recia de un río para capturar los pequeños granos de oro de los sedimentos del río (así como sigue haciéndose hoy). Así, al sacar el vellocino del agua, es, literalmente, un vellocino de oro, transformado por Apuleyo en el toisón mágico. Es un viaje para conocer el misterio de la producción de riqueza y monopolizar el comercio de la zona del Mar Negro. La captura del proceso de capturar el oro del río con el vellocino es la esencia de esta obra. El producto (oro) y el proceso de recogerlo se transforma en esta obra literaria en una búsqueda de algo mágico. El comercio hace riqueza, y es, en revanche, transformado en la literatura, voz de la sociedad y sus pueblos.

Veamos Los nueve libros de historia de Heródoto (484-425 a. de C.) para apreciar cómo, desde las neblinas del pasado prehistórico y el intercambio (trade), se transforma en metáfora literaria el comercio marítimo en la región oriental del Mar Mediterráneo, entre los fenicios, con los cananeos (palabra que, en sí, significa "mercader"). Escribiendo durante el siglo $\mathrm{V}$ a. de $C_{\text {., }}$ es fascinante que Heródoto comience su obra con explicar que, en el primer renglón, ha escrito este documento: (1) para registrar los hechos de hombres, ya sean helenos o algunos bárbaros, (2) para que no sean olvidados, (3) para preservar su gloria (Kleos) y (4) para que las causas de sus hechos sean recordados. Pero lo maravilloso es que Heródoto inmediatamente comienza un recuento del comercio marítimo entre los fenicios y los griegos: 
[...trayendo mercadería de Egipto y Asiria, llegaron a Argos. Ahora Argos estaba en este tiempo la ciudad más importante dentro de la tierra que ahora se llama Hellas; los fenicios llegaron entonces a esta tierra de Argos, y comenzaron a disponer de la carga de su barco. Y en el quinto o sexto día después de que habian llegado, cuando sus bienes habian sido casi todos vendidos, llegó al mar una gran compañía de mujeres, y entre ellas la hija del rey y su nombre, como dicen los Hellenes, era lo, la hija de Ínaco. Estas, paradas cerca del frente del barco estaban comprando los bienes tales que los complacían, cuando de repente, los fenicios, pasando la palabra de uno a otro, corrieron hacia ellas y la gran parte de las mujeres escapó, pero ĺo y otras de ellas fueron raptadas. Así las pusieron en su barco y zarparon hacia Egipto.

Los nueve libros de historia de Heródoto, Libro I, Clío. (Traducción propia)

Es fascinante que Heródoto comience su historia con el "rapto" de Ío, una mujer de Argos, quien viene con otras mujeres al mercado en los muelles de la ciudad, donde está el barco de los marineros mercaderes de Fenicia, quienes la raptan. Después Heródoto cuenta la versión del rapto de Europa y sigue con el rapto de Medea y el toisón mágico de oro, y finalmente con Helena por Alexandros (Paris). Todo eso es el preámbulo de las guerras con los persas. Las fuentes de riqueza, alimentación y comercio son simbolizadas por mujeres raptadas.

Estas cuatro mujeres representan la riqueza de ciudades portuarias y de mercados, emblematizados o simbolizados por las mujeres míticas. Son, al fin de tanto, los fenicios quienes colonizaron el Magreb y Cartago antes de las disputas sobre las rutas marítimas con Roma en las Guerras Púnicas, que eran guerras comerciales por encima de todo. El robo del toisón de oro por Jasón es simultáneo al rapto de Medea de la Cólquide por una tripulación internacional, humana y divina. $Y$ el rapto de Helena de Micenas en Lacedemonia por Alexandros (Paris) es lo que emblematiza el comienzo de la flota de los aqueos para capturar la riqueza del comercio y las rutas comerciales que se cruzan en Troya.

La historia ilustra que los cuatro raptos señalan el comienzo de los pleitos por las riquezas de las ciudades portuarias en la Antigüedad, porque en cada caso la guerra sigue después del secuestro. Heródoto utiliza el logos del robo de mujeres, lo más precioso de una cultura, y también la chispa de celos, luto y 
guerras por la riqueza. Así comienza la obra de Heródoto: con los raptos de estas cuatro mujeres que provocaron las guerras con Persia.

Ahora bien, estos secuestros están contados por los griegos y los persas en diferentes versiones. Algunas versiones aseguran que Ío se enamoró en realidad del marinero fenicio; otras versiones del rapto de Helena declaran que ella fue voluntariamente; y Medea es representada en otras versiones como enamorada de Jasón. Depende de quien escribe o cuenta los eventos, como dice Diodoro Sículo. Para Heródoto, estos cuatro incidentes al comienzo del primer libro de sus Historias, son el preámbulo de conflictos bélicos que tienen sus causas y raíces en la riqueza y el comercio en el Mediterráneo del oriente hasta las orillas más lejos del Mar Negro, desde Argos a Anatolia en el Asia Menor, hasta la Cólquide en el Cáucaso.

Debemos tomar nota de que los fenicios hicieron intercambios comerciales con colonias (emporios) marítimas no solamente en Egipto, sino que también en Tunisia, Malta, Sicilia y Cartago (que cayó en ruinas después de las Guerras Púnicas (150-146 a. de C.).) Estas Guerras Púnicas fueron el resultado de una diáspora de comercio que causó una convergencia cultural con el creciente Imperio Romano. En todos estos lugares, el progreso en el comercio marítimo requería nuevas técnicas en la construcción de barcos, nuevos tipos de barcos, avances en la tecnología de pesos y básculas, en infraestructura y apoyos para las facilidades en las muelles y bodegas en las ciudades portuarias de la Magreb. Resulta una transformación o metamorfosis marítima de la ciudad y la sociedad: un "sea-change", como dicen los ingleses. O sea, un cambio brusco en la marea que cambia toda la composición de una sociedad. O, quizás una sociedad marítima.

Jenofonte (431-355 a. de C.) declara, en su obra On Revenues que la riqueza de Atenas se basó en el poder de su comercio marítimo y las rutas marítimos que ella controlaba en las albores de la guerra civil del Peloponeso de que escribe Tucídides. En Atenas, solamente a los metecos, hombres libres, pero extranjeros, se les permitía practicar el comercio -y el comercio marítimo internacional. Los productos disponibles para la exportación eran sal, pescado salado, aceite de oliva y vino, igual como la plata de las minas en Anfípolis, que eran propiedad del clan de la familia de Tucídides durante el siglo $\mathrm{V}$ a. de C.

Hablando de Tucídides, su obra maestra, La historia de la guerra del Peloponeso — que algunos consideran historia pura, otros, literatura, y otros más la tragedia de Atenas - describe las estrategias de boicots marítimos como sanciones económicas en la guerra Ilevada 
entre Atenas y Esparta. Es decir, el comercio y las rutas marítimas, así como los puertos, siempre son blancos en los conflictos, además de ser causa de guerras.

Atenas aplicó un bloqueo-cumboicot económico como sanción económica contra Megara (ca. 432) un poco antes de que irrumpiera la Guerra del Peloponeso. El decreto implementó un bloqueo militar alrededor de las puertas y mercados de los megarenses en todo el imperio ateniense y así estranguló la economía de Megara y la Megáride en la misma península con Corinto.

Aristófanes, que escribía durante el sexto año de la Guerra del
Peloponeso en su obra, Los acarnienses (II.530-7) menciona cómo este decreto de Atenas contra Megara deja a los pobladores de dicha ciudad en un estado de "hambruna" y los obligó a apelar a los espartanos (y a la Liga del Peloponeso) para obtener ayuda. En su humor absurdo, Aristófanes transforma esta tragedia de boicot comercial en humor e inclusive en una apelación para el fin de la guerra.

Escrito, como se dijo arriba, en el sexto año de la guerra, Diceópolis, el personaje principal de esta comedia, negocia un tratado de paz unilateral con los espartanos y él mismo, como individuo goza de los beneficios de la paz, no obstante la

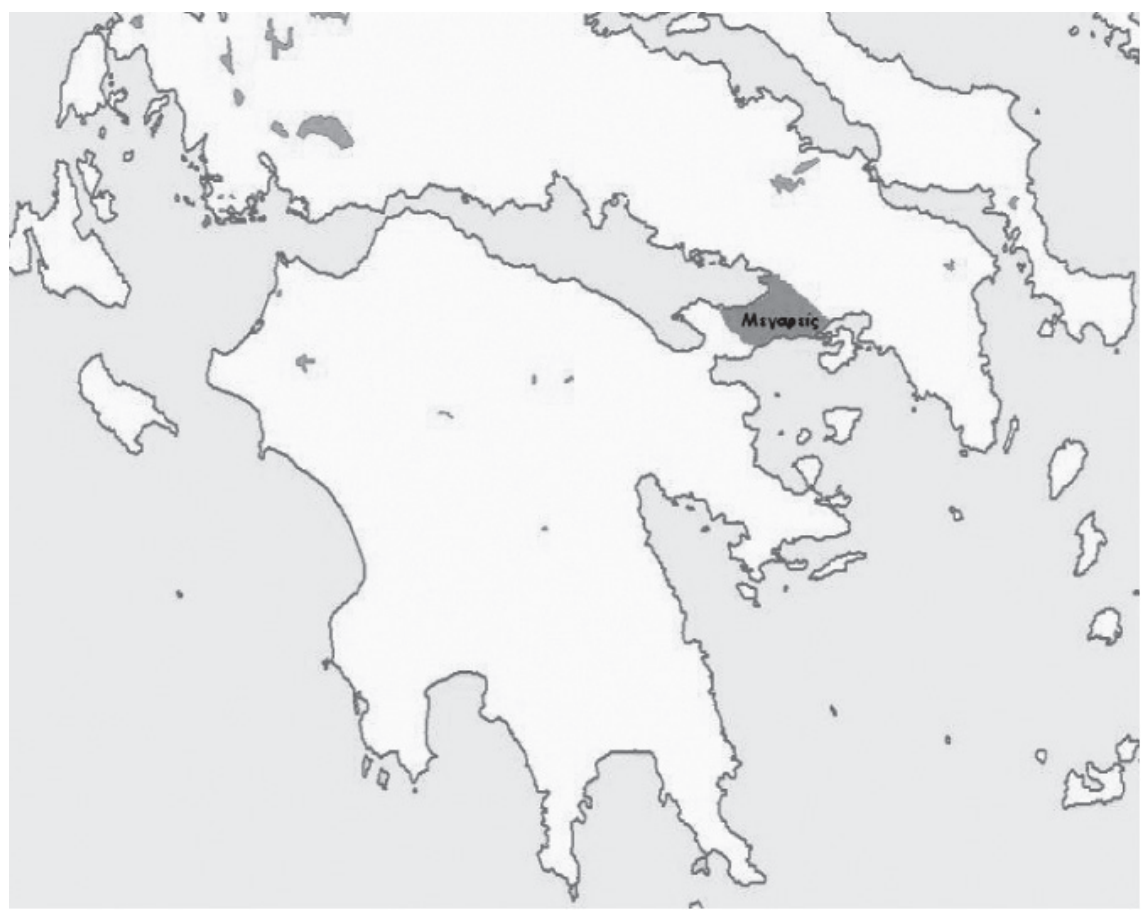


oposición de sus compatriotas atenienses. Esta comedia fue presentada en enero o febrero, durante el festival de Lenaia, cuando solamente los atenienses estaban presentes en la audiencia — sin la presencia de extranjeros. Así, Aristófanes obró con más franqueza ante sus compatriotas. Es una comedia negra y amarga en que, por el hambre resultante del boicot de Atenas contra su ciudad, un padre megarense ofrece a sus hijas a la esclavitud sexual, disfrazadas como cerditas y las intercambia en el mercado negro por ajo y sal. Después, un espía intenta confiscar a las hijas/cerditas como contrabando enemigo. Son comentarios fuertes e irónicos.

No debemos omitir las Guerras Púnicas entre Roma y Cartago. Usualmente esta serie de tres guerras es presentada como una simple agresión en el mundo antiguo, pero en realidad, históricamente, la política internacional plasmada en tratados marítimos entre los dos superpotencias es la verdadera razón.

El puerto más reconocido de la Antigüedad era Cartago, ubicada en el Magreb, que dominó el lado occidente del Mar Mediterráneo. Cartago, ciudad portuaria poderosa fue fundada en 814 a. de C. por los fenicios de Tiro en el Levante. Unos setenta años después, fue fundada Roma y había necesidad de establecer relaciones diplomáticas y comerciales entre Roma y Cartago.
Estos tratados políticos, diplomáticos y comerciales están descritos por Polibio en sus Historias [de Roma, 509 a. de C.]. Cuenta Polibio que llegó el momento en que era necesario que Roma y Cartago firmaran el primer tratado marítimo unos 28 años antes de la invasión de Grecia por Jerjes. Era un tratado entre dos ciudades marítimas que incluyó, entre sus provisiones, que "habrá amistad entre los romanos y sus aliados y los cartaginenses y sus aliados" siempre y cuando los barcos romanos no cruzaron el golfo de Cartago, salvo si fuera por enemigos o tormentas; y si algún barco romano fue empujado a las tierras de Cartago, solamente pudo comprar o tomar lo que necesitaba para la reparación de sus barcos y para rendir homenaje a los dioses y que los barcos mercantes de Roma pudieran operar en Sardinia y Libia solamente en la presencia de un heraldo diplomático cartaginés para que la venta pudiera ser asegurado por el estado. Obviamente este tratado incluyó arbitraje internacional para los intercambios comerciales entre las dos superpotencias, Roma y Cartago, en el Mediterráneo ca. 509 a. de C.

Por su parte, los cartagineses no podían, bajo los términos de este tratado, atacar aquellos asentamientos que estuvieran sujetos a los romanos; no podían construir fortalezas en territorio romano y no podían pasar la noche en el Lacio (territorio romano) 
si andaban armados. Había control militar, entonces, del tráfico marítimo en el Mar Tirreno entre Cartago y Sicilia para hacer valer este primer tratado marítimo en la historia y para formalizar la reciprocidad de las zonas de influencia e intereses comerciales de cada poder.

El primer siglo de la Era Común produce la única novela romana que sobrevive con texto completo. Como obra literaria, El asno de oro de Apuleyo nos abre una ventana a la vida socio-económica de las áreas rurales del norte y Grecia central Tesalia y todo este territorio formaba parte en este entonces del Imperio Romano. Describe con detalles deliciosos la vida de mercados y prácticas religiosos de las ciudades del Magreb y de Macedonia. La novela nos presenta fotografías antiguas, detalladas, realistas y cómicas de la vida cotidiana de la Grecia romana. Esta novela romana y griega lleva por título El asno de oro, no porque el burro se vuelva dorado: era el estilo literario de Apuleyo lo que era dorado; es decir, exquisito.

Por el pecado de curiositas, Lucio es transformado en un asno, pero todavía puede pensar y observar como un hombre para contar su historia, aunque sin poder hablar. En este estado, es brevemente propiedad de un soldado romano, quien lo vende de repente cuando recibe órdenes del Emperador que deberá reportarse inmediatamente en Roma para llevarle una carta.
Este episodio nos revela sistemas de comunicación, comercio y centralización entre Roma y las provincias de Aquea y Macedonia durante el período cuando Grecia formaba parte del Imperio Romano.

Ahora, no hay guarniciones estacionadas, ni retenes, ni aduanas al entrar las ciudades presentadas. Apuleyo presenta la sociedad y su funcionamiento religioso y económico con episodios que ilustran minuciosamente las actividades comerciales para la sobrevivencia de la población pobre del campo. No hay ni policía rural ni urbana, ni fuerzas de las Legiones de Roma presentes, pero, en el transcurso de sus aventuras, Lucio encuentra a su amigo, antes compañero de clase en el mismo colegio: Pitias. Éste, quien ahora es edil del mercado y quiere exhibir su inflada y cómica importancia ante su antiguo compañero haciéndole un favor, interrumpe una transacción comercial en el mercado en la que Lucio le ha comprado a un mercader un pescado podrido a un precio exorbitante. Pitias insiste, en la pomposidad de su poder, en rectificar la situación en beneficio a su amigo, exigiendo que el mercader cambie el pescado podrido por uno fresco. Pero en el altercado, la cena de Lucio - la canasta con el pescado- está tirada en el suelo. Pitias en su afán de ayudar y mostrar su superioridad como oficial del mercado, patea los peces y Lucio se queda ya sin el dinero ni la cena. Ironías del poder y del comercio. 
Las aldeas rurales en esta novela, están presentadas con detalles minuciosos no como centros de producción, sino como centros de intercambio de bienes y contratos de trabajo - todo ello con dinero. Es una economía completamente monetarizada - pero que padece un desempleo crónico. Es una economía de subsistencia. Hay bandidos y ladrones. Apuleyo nos presenta descripciones de cómo los habitantes de la comunidad se organizan y, empuñando antorchas, toman el control de la aldea para protegerse contra los ladrones.

Esta novela romana y griega, en un estilo intricado, cómico y dorado, relata la vida comercial y religiosa de las provincias griegas de Roma y de las ciudades del Magreb -Tunisia- con lujo de detalle, en las aventuras de un joven tesalio y demuestra que el comercio es la base de su trama hasta que Lucio, transformado en asno, come las rosas recetadas de una procesión religiosa y es restituido a su forma humana. La metamorfosis del hombre en animal y de nuevo en hombre presenta la ocasión de ver la sociedad y su funcionamiento en términos del comercio, que incluye la organización de ciudades y aldeas y sus mercados. La magia es el resorte de estas metamorfosis.
El comercio es transformado en la esencia del arte de Apuleyo.

El Salvador no existe fuera del flujo de la historia desde la Antigüedad. Ahora que tendrá un puerto muy importante, está en el camino hacia transformaciones parecidas a los de Grecia, Roma, África y Macedonia. El comercio marítimo de larga distancia e internacional que desarrollará con sus nuevos puertos y ciudades portuarias, Ileva fuertes, bellos y espantosos cambios a la sociedad, inevitablemente.

Deben alistarse los poetas, cineastas y novelistas para capturar la metamorfosis. Las historias aquí presentadas, ya sean mitos o transformaciones, son emblemas de lo que nos viene encima. Para prepararse a entrar en estos cambios, no hay salida más que cerrar la brecha entre el arte de gobernar un estado y los artes comerciales para manejar los nuevos emporios marítimos. $\mathrm{Ni}$ el estado sobrevive sin el comercio, ni el comercio sobrevive sin el estado.

Seguramente hemos avanzado durante los últimos 2,500 años, desde las Guerras Púnicas. Esperamos, no un Platón, sino un Apuleyo.

Marzo de 2011 
LeCtuRAS RECOMENDADAS:

Apuleyo. El asno de oro (México:

Gredos, 2010)

Aristófanes. Las once comedias (México, D.F.: Porrúa, 1978)

Engineering an Empire. Serie de cuatro DVD (9 horas). The History Channel
Heródoto. Historias (Madrid: Gredos, 1977)

Merrills, A.H. History and Geography in Late Antiquity. (Cambridge University Press, 2005)

Polibio. Historias (Madrid: Gredos, 1981)

Tucídides. Historia de la guerra del Peloponeso (Madrid: Cátedra, 2000) 